\title{
Development of meta-subject skills in english language lessons in the context of case technology
}

\author{
M.M. Mamashayeva ${ }^{1}$, A.N. Turdiyev ${ }^{2}$, B.H. Uzokov ${ }^{3}$ \\ ${ }^{1,2,3}$ Teachers of Namangan State University, Uzbekistan \\ Email:mamashayeva_m@umail.uz
}

\begin{abstract}
This article discusses the use of modern technology in the study of foreign languages. The importance of case technology in language learning is revealed. The article offers suggestions and recommendations on the use of this technology.
\end{abstract}

Keywords: methodology, methodology, language, foreign language, modern methods, education, innovative technologies, case technology.

\section{INTRODUCTION}

In modern conditions for the introduction of new educational standards, a significant role in the formation of a new type of educational activity in the main school belongs to the program for the formation of universal educational activities, specific to the age characteristics of students. Important for a modern teacher is that at the same time the formation of all types of universal teaching activities is ensured during the assimilation of all the subjects and their cycles. Particular attention must be paid to this provision to teachers teaching foreign languages, the feature of which is the crystallization of the socio-cultural experience of certain activities provided in other subjects, with the corresponding implementation of meta-subject and objective actions that the student must master as a result of mastering the curriculum program, pedagogical activity in accordance with the individual characteristics of students.

One of the most motivational forms of innovative pedagogical activity in the value system and the formation of the foundations of a worldview in relation to peace, culture, society, and the teaching and control of foreign languages is the compilation of case studies, respectively, the use of case technology in the teaching of a foreign language. The use of this type of activity creates the basis for the formation of the civil identity of the individual, manifests metaprojective links and contributes to the construction of an individual educational trajectory.

\section{MAIN PART}

The main trend in changing the priority goals of school education is to prioritize the development of the student's personality on the basis of his internal potential and in accordance with the best cultural, historical and technological achievements of mankind.

In the context of introducing new educational standards, a significant role in creating a new type of educational activity in the main school belongs to the formation of universal educational activities. For a modern teacher it is important that the development of universal learning activities is ensured in the course of mastering all the subjects and their cycles.

One of the important goals of the educator is to teach competent work with information; the ability to see emerging problems and find the right solutions to them; ability to conduct a discussion, calmly and demonstratively defending their position. To maximize the effectiveness of these universal learning activities (ULA) in the modern educational process, it seems necessary to use innovative activities in classrooms in secondary general education institutions. One of such tools of a modern teacher is the application of case technology. This type of activity in the lessons is not only an activator of the cognitive activity of the learner, but a systemic activation of meta-subjective links.

The most effective is the application of this case to work with pupils of 10-11th grades in the study of topics, since the student-categorical apparatus of students is practically formed, there is 
accumulated life experience for a critical and analytical kind of thinking. The essence of the casetechnology is the need for learners to apply the existing life experience accumulated by the Department of Internal Affairs to form their own position on the material offered by the teacher within a specific topic. The latter should contain a message to the source of the problem, its development, culmination with the presence in the case of some positive and negative views on the subject of the discussion. And the object of consideration can be both scientifically proven facts and everyday situations.

Learners need to analyze the information, identify and select the most important, comprehend the meaning of each paragraph, make assumptions, listen and evaluate alternative options for classmates, formulate conclusions and conclusions.

\section{CONCLUSION}

This kind of work will help students to pay attention to historical facts, the development of the situation with respect to other objects or subjects of the topic, to activate knowledge obtained in other cycles of learning, such as science, social and humanitarian, or even to apply the ULA from mathematics, for example, and probability theory, while expressing their arguments in a foreign language, in particular English.

\section{REFERENCES}

1. G. Lozanov "Suggestology" - Sofia: Science and Art. - 1971

2. Kitaigorodskaya GA The method of intensive instruction in foreign languages. $M$.: High School., 2010

3. DiltsR. "NLP: effective leadership skills" - St. Petersburg. - 2009

4. Asher J.Language by command. The Total Physical Response to learning language // Thewayof learning. Summer -1984

5. Adler G. "NLP modern psychotechnology." SPb - 20116.The main directions in the teaching of foreign languages in the XIX-XX / ed.I.V.Rakhmaninov-M .: "Pedagogy" - 2013 